\title{
Collective Action in Digital Age: A Multilevel Model
}

\author{
Hyunjin Seo \\ The University of Kansas \\ hseo@ku.edu
}

\begin{abstract}
This theory paper proposes a multilevel model for analyzing collective actions for social change in the networked information age. The model includes four levels of agency (individual, group, organizational, and bot) and three levels of affordance (application, network infrastructure, and socio-political system) to help analyze social change dynamics which have become more decentralized. Mechanisms and outcomes of interactions between factors in the model should be considered to offer a more complete picture of social change facilitated by digital communication technologies. Empirical studies based on this model will help illuminate the evolution of communication structures as well as the affordances that evolution provides for social change. Moreover, speedy disintermediation in networked spaces and interactions between the levels in this process provides an opportunity for better understanding information generation and mediation.
\end{abstract}

\section{Introduction}

Collective actions, "actions taken by two or more people in pursuit of the same collective good" [1], have spurred important changes in our society. Examples include sit-in protests against desegregation in the U.S. South in the 1960s and candlelight vigils in South Korea leading up to impeachment of President Park Geun-hye in 2016 [2], [3], [4]. While some collective actions have resulted in influencing public opinion or policies, there are many other examples of collective actions failing to bring about change [5], [6], [7]. How do different factors interact to influence processes and outcomes of particular collective actions? Scholars in different disciplines have grappled with this question [8], [9], [3], [5], [10]. Moreover, the rapidly changing digital media environment makes it even more important to consider different communication agencies and affordances, as detailed later in this paper.

Analyzing collective action and social change dynamics has become more complex, as digital communication technologies have enabled actors beyond traditional intermediaries (e.g., government and mainstream media outlets) to occupy positions of influence. The growth of relatively inexpensive digital collaborative networks has resulted in new capabilities for exchanges of information and opinions between collective action organizers and interested citizens. A recent example is provided by the Women's March on Washington in January 2017, which was aimed at promoting diversity and inclusion in the wake of Donald Trump being elected the U.S. president [11], [12]. Facebook was the primary channel through which participants were mobilized, with hundreds of Facebook event pages created in different cities of the United States and around the world [13]. Other recent examples include Occupy Wall Street and popular uprisings in the Middle East and North Africa [8], [14], [15], [16], [17], [18]. In each of these cases, informally associated citizens have used social media to share information and mobilize people to seek social change.

Consequently, information is generated, filtered, and exchanged without necessarily being mediated by traditional intermediaries. The result is the rapid emergence and extinction of networked spaces as well as of influencers within and between those spaces. In addition, agencies in these spaces often quickly adapt to changes in infrastructure and other affordances for digital-intensive collective actions [19]. Seemingly paradoxically, as information content becomes more decentralized, there arises increased dependence upon shared communication protocols which are largely under the centralized control of governments or largescale service providers [20], [21].

These changes in the communication environment demand new theoretical and methodological approaches to effectively analyze social change dynamics. While some studies have provided important empirical and theoretical arguments about collective action in the digital media age [9], [3], [16], the field still lacks a comprehensive approach to the subject. Indeed, scholars have emphasized the importance of building a theoretical framework that reflects multi-faceted changes brought about by digital communication technologies [7]. [22] argued the field 
is characterized by disjointed initiatives lacking a solid theoretical foundation.

In this theory paper, I propose a multilevel model for analyzing roles of communication for collective action and social change in the networked information age. The model considers four levels of agency (individual, group, organization, and bot) and three levels of structure (application, network infrastructure, and socio-political system). This paper is based on a conceptual research method, which is often used in building a theoretical framework [23]. I argue that this model allows scholars and policy makers to analyze communication for social change in a more contextual and dynamic manner. The argument begins with consideration of relevant contexts in communication and technology, introduces the multilevel model, discusses how the model applies to recent collective actions around the world, and concludes with discussion of scholarly and policy implications of the proposed model.

\section{New Ways of Mobilization Calling for a Comprehensive Framework}

Increasingly available and affordable digital technologies have significant consequences for communication for social change, as demonstrated in recent popular uprisings in the Middle East and Asia [19], [20], [16], [18] and protests around racial and diversity issues in the United States [24], [25]. For example, during the Arab Spring - popular political movements in countries such as Tunisia, Egypt, and Syria since 2010 - social media provided space for both activists and citizens to express dissatisfaction with the status quo and abuse of power by political leaders in their country and thus to create a collective identity against oppression and around resistance [14], [16]. Pro-democracy protesters in Hong Kong in 2014 utilized social media for organizing and sustaining their movement calling for election reform [19]. South Korean activists and citizens used social media to mobilize people for candlelight vigils for six weeks in 2016 calling for impeachment of President Park Geunhye who was implicated in a corruption scandal [4].

In the United States, social media have recently emerged as an important collection of spaces for mobilizing for racial, ethnic, or gender-related issues. For instance, \#Fergerson and \#BlackLivesMatter are among the most influential hashtags around social causes in Twitter's 10-year history [24], [25]. A more recent example is the Women's March on Washington in January 2017, "the largest single-day demonstration" in recorded U.S. history [11]. Devastated by the U.S. presidential election results on the night of November 8, 2016, a woman living in
Hawaii created a Facebook page for a hypothetical march in Washington D.C. [13], [26]. Her post received about 10,000 responses by the next morning, and then experienced activists joined the cause to create a committee for an actual march in Washington D.C. on January 21, 2017 [11], [27]. Through the process, Facebook was used as the primary medium through which both organizers and participants promote their agenda of improving rights of minority groups including LGBTQ as well as women's rights. Digital communication technologies have enabled mobilization of individuals seeking common goals and influenced how organizations identify and select activists who are considered beneficial to collective action [3], [28], [29].

These changes in the nature of interactions between actors in society, facilitated by increasingly available collaborative communication technologies, are described in many different terms such as information society [30], network society [31], [32], [33] and networked information economy [34]. Castells [31], [32], [33] used the term network society to describe the impact of information communication technologies (ICTs) on different levels of interactions in society. According to Castells [31], a network society is "a society whose social structure is made of networks powered by microelectronics-based information and communication technologies" (p. 3). Benkler [34] argues that ICTs have brought about a networked information economy characterized by information decentralization, nonproprietary strategies, nonmarket mechanisms, and more effective large-scale non-hierarchical cooperation. Examples of the networked information economy include wikis, blogs, and open-source software through which an unlimited number of individuals can collaborate to produce and share information and ideas. Internetbased information and communication technologies have brought about important changes in our society, particularly with regard to producing and sharing information and knowledge. These underlying changes have significant implications for collective actions for social change.

Studies have examined specific roles of digital communication technologies in collective actions. For example, [8] analyzed the correlation between protests, arrests, and spikes in event mentions in social media by looking at three different cases: the 2011 anti-austerity movement in Spain (Indignados), the 2011 Occupy movement, and the 2013 Vinegar protests in Brazil concerning a raise in public transportation fare. Analyzing time-series data of Twitter, Facebook, and online protests, the research found that content on Twitter and Facebook predicted future outbreak of onsite protest activity for two of the 
three cases. Another study [17] examined how Twitter was used to mobilize protest action during the Occupy Wall Street protests in the United States, Indianados in Spain, and Aganaktismenoi in Greece. The results from the study's comparative content analysis of tweets suggested that Twitter was primarily used for political discussion and to share protest information. However, Twitter was not actively used for calls for participation in the collective actions. [35] found that social media is "emancipatory with regard to structural constraints, but hegemonic with regard to an important content restriction (i.e., frames)."

While these studies are helpful, research that takes into account both structural and behavioral aspects, as well as physical and cyber domains, of communication aspects is lacking. Communication networks provide affordances for the flow of messages among communicators. As such, the structure of those networks is not neutral to the forms and content of information that traverses them. Changes in communication networks influence types of communication tools used, ways of interactions between communication actors, and modes of shared content. Moreover, behaviors of individuals or organizations are patterned and often enabled by structural aspects of systems within which they operate [19], [34]. Based on their analysis of microblogging use during the Gulf of Mexico oil spill, [36] showed how different actors (e.g., advocates, supporters, and amplifiers) played emerging and independent roles while demonstrating distinct patterns of technology use.

Thus, it is important to understand both structural conditions and behavioral aspects and interactions between the two in analyzing collective actions in the networked information age. This paper proposes a multilevel model considering these aspects to offer a fuller understanding of social change dynamics in the networked information age.

\section{Method}

This paper is based on a conceptual research method [23] and identifies taxonomies of agency and affordance based on a review of the literature in the area as well as examinations of recent collective action initiatives. The focus is on a world of interconnected networks in terms of agency and affordance rather than comprised simply of independent and dependent variables. These suggested taxonomies could be used to analyze how different types of agency and affordance influence the scope, immediacy or other processes and outcomes of collective actions.

\section{Multilevel Model of Collective Action in the Digital Age}

In developing a theoretical model for social change dynamics in the networked information age, different factors need to be analyzed. For example, [37] argued that "political, economic, social, and environmental resources structure possibilities for social change," and thus these conditions should be considered, instead of conceptualizing development "in a narrow sense of hierarchical centralized planning or of localized participation" (p. 139-140). Some scholars have advocated for multilevel theorizing in the areas of social change communication or conflict communication to provide a more holistic understanding of related topics [37]. The multilevel model of collective action proposed in this paper includes four levels of agency (individual, group, organization, and bot) and three levels of affordances (application, network infrastructure, and socio-political system). Please refer to Figure 1 for an overview.

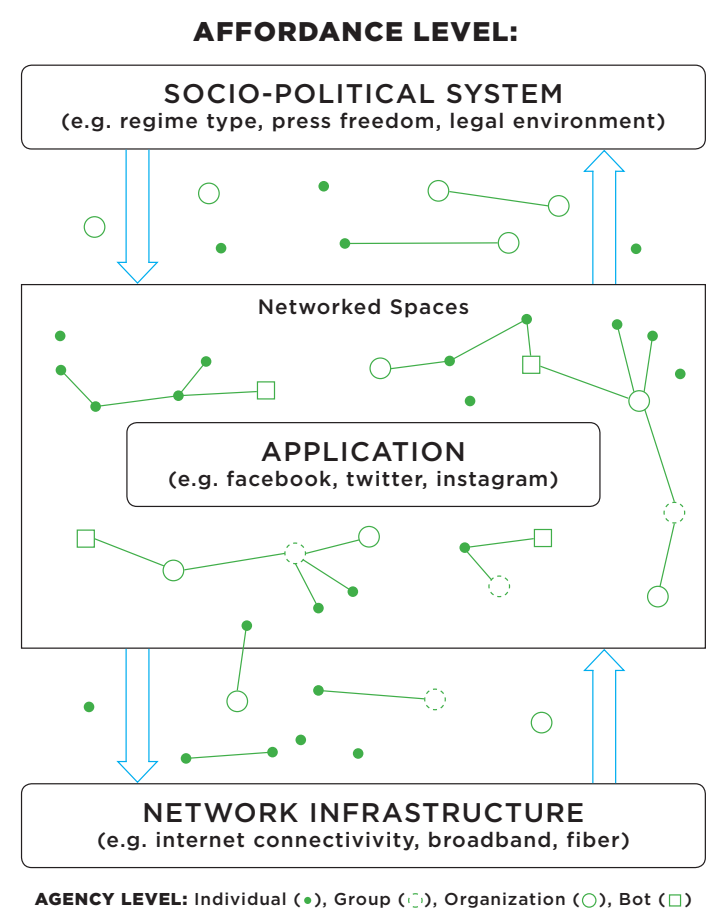

Figure 1. Affordance and Agency Model

\subsection{Agencies}

In discussing collective action in the digital media age, both human agency and material agency should be considered [38, 39]. [38] argued that scholars need to revise theories of agency in sociotechnical systems 
to reflect a "symbiotic relationship" between technical and human elements. While previous research on collective action tends to focus either on individual activists or on organizations [3], [8], focusing on one type of agency is limiting. For example, while it is true that increasing availability and affordability of digital communication technologies have enhanced "individual agency" in collective action efforts [3], organizations also utilize these technologies for collective action. Therefore, examining agency at different levels is essential for a more comprehensive understanding of collective action in this digital age.

In their study introducing a conceptual framework to study social movements and the media, Mattoni and Treré [40] consider three societal levels: (i) micro level, (ii) meso level, and (iii) macro level. The micro level focuses on individual activists whereas the macro level deals primarily with political culture that shapes mobilizations and activist-media relationships. Situated between the micro and macro levels, the meso level concerns collective formations by individuals whether they are called movement organizations, groups or networks. While this approach provides a useful guidance, a clear distinction between agency and structure aspects would help future analysis.

The multilevel model proposed in this paper has four levels on the agency axis: (i) individual, (ii) group, (iii) organization, and (iv) bot. At the individual level, activists or ordinary citizens may share information or opinions via their social media accounts such as Facebook or Twitter. Recent research and reports have indicated that individual activists have embraced popular social media sites in promoting their causes or mobilizing people [14], [19], [41]. In the wake of the South Korean Sewol ferry disaster in 2014, South Koreans used social media channels such as Kakao Talk to mobilize protests against the South Korean government for its perceived "mishandling of the situation" [42]. In December 2017, citizens in Iran used Telegram and Instagram to organize demonstrations in multiple cities that demanded removal of Supreme Leader Ayatollah Khamenei [14]. These are only few of the many examples in which popular social media platforms have facilitated the creation and dissemination of collective action messages at the individual level.

Social media facilitate forming groups around common causes. Groups in this context are different from organizations in that the former tends to last for a shorter term and lack formalities as compared with the latter. For example, the Women's March in 2017 started with individual interactions on Facebook, evolved into multiple Facebook groups around the United States, and finally resulted in creation of the March On, an organization founded by leaders of
Women's March protests [11], [12]. Compared with the March On, those Facebook groups were more decentralized. In these groups, some citizens function as content producers and information moderators influencing behaviors of other citizens. In this paper, these citizens are called social influencers to distinguish them from traditional influencers or intermediaries of information such as mainstream media outlets. While citizens are traditionally thought of as audience members or content consumers, these network spaces combined with the affordances they provide allow these citizens to be content producers with influence on their peers [41]. That is, in these network spaces, information propagation and diffusion is less and less influenced by traditional intermediaries such as mass media with the gap filled by social influencers.

At the organizational level, governments, mass media entities, or advocacy groups share news or information related to particular social issues [9] [44]. In particular, nonprofit organizations have become less reliant on news media, as they now utilize their own communication channels such as websites or social media platforms to share information about their causes and campaigns [45], [46]. For example, the American Red Cross and the March On use various social media sites to share information about their activities and enhance citizens' participation in their campaigns [11], [12].

Finally, bots (short for software robots), algorithms, or other automation methods have emerged as an important producer of content related to social and political issues [38], [47]. In particular, social bots, computer algorithms that automatically generate content and interact with people on social media, have increasingly become an important part of conversations on social media, whether positive or negative [47]. For example, [48] found that bots played a key role in Brazil's anti-corruption protest on Twitter. They found that bots influenced the protest by amplifying messages as they replicated particular messages on Twitter. The authors argued that neglecting bots in studying online activism can post "threats to research validity" (p. 41). Similarly, [49] argued that "the role of bots is evolving from one of support to one of active content creation," pointing out that bots accounted for $15 \%$ of Wikipedia edits as of 2014 (p. 3). They argue that bots, as active contributors in co-production processes, "are situated to influence bias and influence disparities in digitally co-produced information" (p. 6). In the United States, there have been growing concerns about how Russian-produced bots are used to spread misinformation around the world in recent elections around the world including the 2016 U.S. presidential election. 
In this sense, recent studies have emphasized the importance of taking into account bots in examining agencies. [38] call bots as "symbiotic agency," as "people project various intentions and emotions onto bots and other emerging technologies and ascribe agency to them to explain their behaviors" (p. 4916). [38] argue that while an agentic perspective doesn't generally consider nonhuman as agents, actor-network theory started theorizing "nonhuman agency" to gain a better understanding of human capabilities and human-nonhuman dependencies.

\subsection{Affordances}

Another multilevel category in the model is affordance, which refers to action possibilities in the environment in relation to the action capabilities of an actor. In the proposed model, affordance is composed of three levels: (i) application, (ii) network infrastructure, and (iii) socio-political system. The concept of affordance has provided a theoretical framework for analyzing interactions between people and technology and explaining effects of user intentions and technology capabilities and vice versa [50], [51]. It is important to consider communication affordance at the application level, as technological affordances available on a particular application influence types of communication behavior. In particular, specific interactive or privacy features allowed in an application (e.g., Facebook group vs. Yik Yak group) affect interactions and connections among actors and types of content generated by actors. Networked spaces are formed on these applications. Networked spaces are social communities such as Facebook groups or online chat rooms. People have used different terms to describe this digital space. Noting political and cultural implications of this space, [18] called it "digital spaces of contention," to refer to "an amalgam of social interactions, citizen forms of engagement, cultural practices, ordinary activities, and mundane pursuits that intersect with and embedded in media experiences, anchored in participatory networks, and intertwined with processes of communication" (p. 12-13). Networked spaces are dynamic and adaptable to changes in the communication network infrastructure and needs of particular social or political movements. Participants in social or political movements moved from one application to another to maintain a space in the face of disruptions at the network infrastructure layer. Examples include South Koreans transferring from Kakao Talk to Telegram Messenger and Hong Kong protesters moving from the global Internet to peer-topeer wireless mesh networks in 2014 [19], [42].
Communication network infrastructure provides opportunities to create networked spaces and consequently motivating particular communication behaviors in those networked spaces. Current Internet network infrastructure consists of multiple components including Internet Protocol (IP) connectivity and physical units such as broadband, router, and fiber. Creation and mutation of these components will influence affordances for social movements provided at the network infrastructure level. For this reason, authoritarian governments often disrupt the network infrastructure in attempts to contain social or political movements for social change [52], [53]. Changes in the communication infrastructure such as disruption of Internet connectivity affect types of communication channels used and modes of interactions among activists. In Libya, when Gaddafi shut down mobile providers and ordered telecommunication companies to close Internet access, a relatively new mobile service provider in Libya, which was less centralized and less affected by the Gaddafi government, used home location register (HLR) and other means to help support mobile phone system in some parts and provided free service throughout the uprising [52], [53]. In addition, foreign companies arrived in Libya to open a new cellphone network in 2011. Limited Internet connections supported by these efforts enabled use of Skype calls and MSN chats in and from Libya, permitting the uprising to keep its momentum.

A country's political system or regime type is an important factor in the country's adoption of the Internet and freedom given to its citizens in terms of using digital technologies [54], [55]. For example, based on an analysis of 200 countries from 1991 to 2011, [55] showed political institutions influenced the diffusion of the Internet even when taking into account countries' economic developments or other related factors. Similarly, [54] found democratic countries are more likely to adopt the Internet and other digital communication technologies. They also argued that the adoption and spread of the Internet around the world are influenced by economic, regulatory and sociopolitical characteristics of countries and their evolution overtime. In this sense, it is important to consider a country's political system and social and economic conditions in developing a model for communication for social change. Indeed, some scholars emphasized this by pointing out that "assertions about the technology's political effects are usually made without consideration of the full national contexts in which the Internet operate in any given country" [56]. 


\subsection{Agency-affordance interactions}

This model allows us to better consider both structural and behavioral aspects with regard to collective action. Characteristics of communication affordances at the application, communication network infrastructure, and socio-political system levels often significantly influence behaviors of different types of agency (individual, group, organization, and bot). Some affordances are more closely associated with certain types of agencies. For example, compared with formal organizations, individuals and groups are likely to more quickly adjust their communication behaviors in response to structural changes at the application level, as they don't require multiple chains of decision-making processes. In addition, the emergence of high-speed social collaborative packet switched networks has brought a shift from "the mass-mediated social spaces" to "networked public spheres" [34]. These networked public spaces facilitate rapid creation, distribution, and deletion of communication contenttext, still image, video, and audio - in one-to-one or one-to-many communication conditions.

During the pro-democracy protests in Hong Kong in 2014, protesters tried to get around automatic filters by the Chinese government by intentionally misspelling words or writing in code [19]. Moreover, FireChat - an "off-the-grid" smartphone app developed by a Silicon Valley start-up - emerged as an important communication tool among protesters as the Internet connectivity significantly slowed down in the area [57], [58]. During the first two weeks of the protests, FireChat registered about 500,000 downloads in Hong Kong with 10.2 million chat sessions and 1.6 million chatrooms [58]. FireChat served as "a giant megaphone" during the Hong Kong protest, as the app is not limited to a user's circle but messages on FireChat available for the public to see.

Amid the Park Geun-hye government's pledge to prosecute people spreading rumors about her dealing with the Seowol ferry incident in 2014, South Koreans migrated from the popular Kakao Talk app to an encrypted messaging service called Telegram Messenger to avoid government censorship [42]. Telegram Messenger utilizes end-to-end encryption providing a "secret chat" option and gained 1.5 million new South Korean users within seven days [42].

Examining different types of agency and affordance and interactions between them offers a robust picture of collective action initiatives in the digital age. The effects of changes in one level on the other levels and how those changes combine to help us understand the joint roles of each level. Multilevel theoretical frameworks - informed by longitudinal and interdisciplinary empirical research - are crucial to developing nuanced understandings of social interactions. Next, I illustrate the multilevel framework by considering the latest conflict in Syria.

\section{Applying the Model to Empirical Research: Syria Example}

In examining mechanisms and outcomes of interactions of the agency and affordance levels, a researcher could focus on recent social and political movements that received international attention (e.g., Syria, Egypt, Hong Kong, and South Korea). The researcher could select countries that differ in terms of country network infrastructure, social media use, Internet policy, and cultural and legal environments.

The ongoing Syrian conflict, which began in 2011 with popular uprisings against Syrian President Bashar Hafez al-Assad [59], [60], [61], highlights the importance of examining the three affordance levels and the four agency levels to develop a more robust understanding of political/social protests in the context of networked digital information. Pro-democracy protests on the streets of Syria in 2011 quickly garnered support on popular social media sites such as Facebook and Twitter (application level), generating social interactions within Syria and with supporters outside Syria at the networked spaces afforded by digital communication technologies [20], [62]. Individual activists in Syria used social media to expose actions of the Assad regime to the international community, to exchange information and tactics with other revolutionaries both within and outside of Syria, and to spread their messages related to resistance activities [20], [62]. Their social media use also helped them to develop and spread a revolutionary narrative of support for democratic change and opposition to the Assad regime. For example, rebels used YouTube to show brutalities of the Assad regime and tell their stories. At the group level, a dozen Facebook groups were formed with users in and outside the country who are loosely connected sharing information and resources. At the organizational level, main opposition groups such as the National Coalition of Syrian Revolution and Opposition Forces engaged in interviews with foreign media and posted information on social media sites to share their message of resistance to the Syrian government [20].

However, constraints on communication technology at the socio-political system and the network infrastructure levels influence activities of individuals, groups, and organizations. At the sociopolitical system level, Syria is a non-democratic country ruled by a dictator that suppresses freedom in politics, civic engagement, and media operations [63]. 
The country has been consistently rated "not free" in political freedom and press freedom by freedom rating organizations such as the Freedom House and the Reporters Without Borders. These characteristics at the socio-political system level along with Syria's low economic developments are associated with low penetrations of the Internet and other communication technologies [63]. At the network infrastructure level, only about 6 million people in Syria used the Internet as of 2017 with the penetration rate of 31.9 percent [64]. While this is an increase from 30,000 in 2000 and is in line with increased Internet connectivity in the MENA region in recent years, availability and affordability of the Internet in Syria is far inferior compared with other countries in the region or around the world [19], [64].

Moreover, the Syrian government disrupted the network infrastructure to oppress activities in networked spaces at the application. For example, in November 2012 and May 2013 the Syrian government shut down the Internet across the country and cut cellphone services in certain areas where oppositions forces were active [65]. While rebels in Syria were struggling to create alternative social collaborative spaces online, Syrian diaspora activists have supported the Syria-based opposition's efforts by telling stories of civilian sufferings in Syria via social media [66]. In both 2012 and 2013, the Internet connectivity was restored within days.

In addition to the disruption at the network infrastructure level, the Syrian government directly attacked the opposition's social collaborative networks formed at the application level. The Syrian government shut down websites critical of the regime and trolled Twitter accounts and Facebook pages. It also monitored and tracked down dissenters, and on occasion subjected them to torture for more information. The Syrian government has accomplished these largely through the Syrian Electronic Army, dubbed as "Assad's cyber warriors" and considered an extension of the regime itself [67]. The activities of the Syrian Electronic Army have extended to other countries. For example, it hacked the Twitter account of the Associated Press and proclaimed that U.S. President Barack Obama had been injured in an attack on the White House, causing the U.S. stock market to crash within minutes [68]. In 2015, the Syrian Electronic Army claimed credit for taking down the U.S. Army's public website. Syrian President Bashar al-Assad's government has also capitalized on social media to promote its political agenda [20], [62], [67]. For example, the Syrian government created spambots to create messages supportive of the Syrian regime.
Several empirical data collection and analyses could be conducted. First, a researcher could conduct interviews with movement organizers in Syria who are identified through an analysis of tweets and other social media content popular during the movements as well as media reports and other documents on the movements. Interview data could provide important context for analyzing digital media-facilitated social movements or collective action in the countries by helping understand strategies employed to mobilize citizens through social media sites.

Second, the investigator could analyze social media content generated during the protests to identify primary topics and themes. The researcher could focus on Twitter and Facebook data retrieving relevant content using $\mathrm{R}$ and niche crawlers. In doing so, it is important to analyze messaging. Discourse, topic, callto-action message, and content format should be closely examined. How the discourse of a social change campaign fits with larger societal and cultural issues is an essential component of assessing the campaign. Classifying social media posts based on the topic and call-to-action message will allow researchers to analyze what types of content in terms of substance might influence the outcomes of the campaign even when controlling for other variables at the agency and affordance levels. Analyzing content format-e.g., text only, visual, link or emoji-helps understand how the style of content might influence such outcomes. In addition, this analysis could provide insight into the formation and evolving of functional communities at the networked-space level.

Finally, to determine how changes in the networkinfrastructure level influence social interactions in both the socio-political system and application levels, the researcher could analyze associations between Internet connectivity and disruptions in the network infrastructure, as well as the volume and characteristics of movement-related content. Empirical data to be used to examine the networkinfrastructure level include domestic and international Internet connectivity, autonomous system number (ASN) connectivity, and IP address connectivity data as curated by TeleGeography's Global Internet Geography service. Since influences across the levels may be delayed, the researcher should conduct longitudinal, time-series analyses. To curate a dataset appropriate for time-series analyses, the researcher could first establish a timeline of main protest activities and then document levels of on-site demonstrations and other relevant activities by adopting the protest event analysis approach [8], [70]. Data sources in this particular area could include press reports, government documents, and information curated by nongovernmental organizations. 
Results from analysis such as this could advance understandings of connections between movementrelevant social collaborations enabled by a variety of networking applications and social change. Within a network, members interact with and influence one another and are influenced by the views of others. Such an empirical study analyzes influencers and their potential interactions in both socio-political system and application levels to identify critical influencers to a particular movement and thus to help develop facilitation or mitigation strategies at those levels.

\section{Conclusion}

This paper proposed a multilevel model for analyzing collective actions for social change in the networked information age. I argue mechanisms and outcomes of interactions of levels presented in the model should be considered to understand social change dynamics in the digital media age. The model should be refined based on additional empirical research studies in the area. For example, one could analyze political movements in countries that offer varying degrees in terms of country network infrastructure, social media use, and Internet policy. Examining communication phenomena in different countries or cultures is essential to develop a more comprehensive understanding of communication dynamics in the digital media age [19]. Empirical data for this could include domestic and international Internet connectivity, levels and characteristics of activities in networked spaces, patterns of connections among actors, and visual and textual messages generated in the networked spaces. Identifying social influencers and understanding their roles in the process of information propagation is also essential. In addition, social media platforms have become important channels for spreading images with both manifest and latent meanings in conflict situations, as demonstrated by Twitter images during recent Israeli-Hamas conflicts and graphic Internet videos by the self-proclaimed Islamic State. Visuals will continue to rise in popularity in this digital media age, as people opt for content that is attentiongrabbing and easy to understand. Consequently, it is important to understand both textual and visual content. Additionally, cultural variability needs to be considered. As widely documented, culture shapes both verbal and nonverbal communication behaviors [71] and cultural variability should be considered at the three levels to more accurately capture the role of culture in formation and dissemination of communication cues in social interactions. Culture provides an important context for understanding social change initiatives in a particular society [72].
In empirically testing the multilevel framework, recent movements in Hong Kong and South Korea could provide important opportunities. During the prodemocracy protests in Hong Kong in 2014, protesters utilized social media services for organizing and sustaining their movements calling for election reform [19]. Moreover, FireChat - an "off-the-grid" smartphone app developed by a Silicon Valley startup-emerged as an important communication tool among protesters as the Internet connectivity significantly slowed down in the area [58]. Social media have been an important part of political movements in South Korea-one of the world's most wired countries where the Internet plays a large role in social relations [64]. South Korean activists and citizens used social media to mobilize people for candlelight vigils for six weeks in 2016 calling for impeachment of then President Park Geun-hye who was implicated in a corruption scandal. In the wake of the Sewol ferry disaster, South Koreans used social media channels to mobilize protests against the government for its "mishandling of the situation" [42]. While these protests may have taken place even without these digital networks, information infrastructure influenced their immediacy and scope by providing channels for activists/citizens to express dissatisfaction and create a collective identity [69].

In conducting empirical research, it will prove useful to adopt an interdisciplinary research approach incorporating concepts and methods from disciplines including sociology, political science, economics, and computer science. Theory-driven empirical studies will help illuminate the evolution of communication structures as well as the affordances that evolution provides for social change. Moreover, speedy disintermediation in networked spaces and interactions between the levels in this process provides an opportunity for better understanding information generation and mediation in this rapidly changing media environment. This model also offers implications for other related issues such as how to mobilize influencers to detect and combat disinformation campaigns which have affected many different countries in recent years [73].

\section{References}

[1] G. Marwell and P. Oliver, The Critical Mass in Collective Action, Cambridge: Cambridge University Press, 2007.

[2] M. Biggs and K. T. Andrews, "Protest Campaigns and Movement Success," American Sociological Review, 2015, $80(2)$.

[3] B. Bimber, A. Flanagin, and C. Stohl, Collective Action in Organizations: Interaction and Engagement in an Era of 
Technological Change, Cambridge University Press, 2012.

[4] H. Ock, Candle revolution: how candles led to Park's impeachment, The Korea Herald, 2016, December 9.

[5] T. R. Davies, The failure of strategic nonviolent action in Bahrain, Egypt, Libya and Syria: "political ju-jitsu" in reverse. Global Change, Peace \& Security, 2014.

[6] S. Staggenborg, Social Movements, Oxford University Press, 2015.

[7] K. G. Wilkins, T. Tufte, and R. Obregon, The Handbook of Development Communication and Social Change (1 edition), Chichester, West Sussex, UK Malden, MA: Wiley-Blackwell, 2014.

[8] M. T. Bastos, D. Mercea, and A. Charpentier. Tents, Tweets, and Events: The Interplay Between Ongoing Protests and Social Media. Journal of Communication, 65(2), 320-350. 2015.

[9] W. L.Bennett and A. Segerberg, The Logic of Connective Action: Digital Media and the Personalization of Contentious Politics, Cambridge University Press, 2013.

[10] A. D. Morris and C. M. Mueller, Frontiers in Social Movement Theory, Yale University Press, 1992.

[11] E. Chenoweth and J. Pressman, This is what we learned by counting the women's marches, Washington Post, 2017, February 7.

[12] G. Frazee, What the Women's March wants. PBS NewsHour, 2017, January 18.

[13] I. Lapowsky, The Women's March Defines Protest in the Facebook Age. WIRED. 2017, January 21.

[14] M. Brocchetto and D. Andone, Iran restricts social media as anti-government protests enter fourth day. CNN, 2017, December 31.

[15] B. Gleason, \#Occupy Wall Street: Exploring Informal Learning About a Social Movement on Twitter, American Behavioral Scientist, 57(7), 966-982, 2013.

[16] P. N. Howard and M. M. Hussain, The Role of Digital Media, Journal of Democracy, 22(3), 35-48, 2011.

[17] Y. Theocharis, W. Lowe, J.W. van Deth, and G. García-Albacete, Using Twitter to mobilize protest action: online mobilization patterns and action repertoires in the Occupy Wall Street, Indignados, and Aganaktismenoi movements, Information, Communication \& Society, 18(2), 202-220, 2015.

[18] M. Zayani, Networked Publics and Digital Contention: The Politics of Everyday Life in Tunisia, Oxford University Press, 2015.

[19] E. Parker, Social Media and the Hong Kong Protests, The New Yorker, 2014, October 1.

[20] Author, 2012

[21] Author, 2015

[22] P. Thomas, Development communication and social change in historical context. In The Handbook of Development Communication and Social Change (pp. 7-
19). Wiley-Blackwell, 2014.

[23] J. Meredith. Theory building through conceptual methods. International Journal of Operations \& production Management, 13(5), 3-11, 1993.

[24] M.Anderson and P. Hitlin, Social Media Conversations About Race, Pew Research Center, 2016, August 15. Retrieved November 29, 2016.

[25] T. Sichynsky, These 10 Twitter hashtags changed the way we talk about social issues, Washington Post, 2016, March 21.

[26] N. Agrawal, Women's marches live updates: Millions march in L.A. and around the world following Trump's inauguration, Los Angeles Times, 2017, January 21.

[27] T. Wallace and A. Parlapiano, Crowd Scientists Say Women's March in Washington Had 3 Times as Many People as Trump's Inauguration, New York Times, 2017, January 22.

[28] T. Ashuri and Y. Bar-Ilan, Collective Action Recruitment in a Digital Age: Applying Signaling Theory to Filtering Behaviors. Communication Theory, 27(1), 70 91, 2017.

[29] J. Earl and K. Kimport, Digitally Enabled Social Change: Activism in the Internet Age, Cambridge, MA: MIT Press, 2011.

[30] F. Webster, Theories of the Information Society (3 edition), Routledge, 2006.

[31] M. Castells, Materials for an exploratory theory of the network society1. The British Journal of Sociology, 51(1), 5-24, 2000.

[32] M. Castells, Ed., The Network Society: A CrossCultural Perspective (illustrated edition edition), Cheltenham, UK; Northampton, MA: Edward Elgar Publishing, 2004.

[33] M. Castells, The Rise of the Network Society: The Information Age: Economy, Society, and Culture, John Wiley \& Sons, 2011.

[34] Y. Benkler, The Wealth of Networks: How Social Production Transforms Markets and Freedom, Yale University Press, 2006.

[35] S. M. Miranda, A. Young, and E. Yetgin, Are social media emancipatory or hegemonic? Societal effects of mass media digitalization in the case of the SOPA discourse, MIS Quarterly, 40(2), 303-329, 2006.

[36] E. Vaast, H. Safadi, L. Lapointe, and B. Negoita, An examination of microblogging use during the Gulf of Mexico oil spill, MIS Quarterly, 41(4), 1179-1205, 2017.

[37] K. G. Wilkins, T. Tufte and R. Obregon, The Handbook of Development Communication and Social Change (1 edition), Chichester, West Sussex, UK Malden, MA: Wiley-Blackwell, 2014.

[38] G. Neff and P. Nagy. Automation, algorithms, and politics- talking to bots: Symbiotic agency and the case of 
tay. International Journal of Communication, 10, 2016.

[39] P. M. Leonardi, When Flexible Routines Meet Flexible Technologies: Affordance, Constraint, and the Imbrication of Human and Material Agencies, MIS Quarterly, 35(1), 2011.

[40] A. Mattoni and E. Treré, Media Practices, Mediation Processes, and Mediatization in the Study of Social Movements, Communication Theory, 24(3), 252-271, 2014.

[41] T. Poell, Social media and the transformation of activist communication: exploring the social media ecology of the 2010 Toronto G20 protests, Information, Communication \& Society, 17(6), 716-731, 2014.

[42] BBC, \#BBCtrending: Why South Koreans are fleeing the country's biggest social network, 2014.

[43] C. Li and J. Bernoff, Groundswell: Winning in a World Transformed by Social Technologies, Harvard Business Press, 2011.

[44] A. Segerberg and W. L. Bennett, Social Media and the Organization of Collective Action: Using Twitter to Explore the Ecologies of Two Climate Change Protests, The Communication Review, 14(3), 197-215, 2011.

[45] C. Guo and G. D. Saxton, Tweeting Social Change: How Social Media Are Changing Nonprofit Advocacy, Nonprofit and Voluntary Sector Quarterly, 43(1), 57-79, 2014.

[46] K. Lovejoy and G. D. Saxton, Information, Community, and Action: How Nonprofit Organizations Use Social Media, Journal of Computer-Mediated Communication, 17(3), 337-353, 2012.

[47] E. Ferrara, O. Voral, C. Davis, F. Menczer, and A. Flammini, The rise of social bots, Communications of ACM. 59(7), 96-104, 2016.

[48] C. Salge and E. Karahanna, Protesting corruption on Twitter: Is it a bot or is it a person? Academy of Management Discoveries, 4(1), 32-49. 2018.

[49] A. Young, A. D. Wigdor, and G. Kane. Theorizing Human and Bot Co-production Effects on Information Quality. International Conference for Information Systems. 2018.

[50] A. Majchrzak, S. Faraj, K. Gerald, and B. Azad, The contradictory influence of social media affordances on online communal knowledge sharing, Journal of ComputerMediated Communication, 19(1), 38-55, 2013.

[51] M. K. Ahuja, P. Patel, and A. Suh. The influence of social media on collective action in the context of digital activism: An affordance approach. Proceedings of the $51^{\text {st }}$ Hawaii International Conference on System Sciences, 2018.

[52] M. Coker, and C. Levinson, Rebels Hijack Gadhafi's Phone Network. Wall Street Journal, 2011, April 13.

[53] E. Hill, How “rebel" phone network evaded shutdown - Al Jazeera English. Al Jazeera, 2011.

[54] M. F. Guillen and S. L. Suarez, Explaining the Global Digital Divide: Economic, Political and Sociological
Drivers of Cross-National Internet Use, Social Forces, 84(2), 681-708, 2005.

[55] H. V. Milner, The Digital Divide: The Role of Political Institutions in Technology Diffusion, Comparative Political Studies, 39(2), 176-199, 2006.

[56] S. Kalathil and T. C. Open Networks, Closed Regimes: The Impact of the Internet on Authoritarian Rule, Washington, D.C: Carnegie Endowment for Int'l Peace, 2002.

[57] N. Cohen, Hong Kong Protests Propel FireChat Phone-to-Phone App, New York Times, 2014, October 5.

[58] P. Shadbolt, FireChat, the app behind Hong Kong's protests, CNN, 2014. Retrieved from goo.gl/hyQ6vN

[59] R. Erlich, Inside Syria: The Backstory of Their Civil War and What the World Can Expect, Prometheus Books, 2014.

[60] BBC, Syria: The story of the conflict, 2015.

[61] Committee to Protect Journalists, How many more? CPJ remembers journalists killed. Retrieved December 29, 2015, from goo.gl/DkEmzx

[62] A. Shehabat, The social media cyber-war: The unfolding events in the Syrian revolution 2011, Global Media Journal, 6(2), 1-9, 2012.

[63] Freedom House, Syria Profile, 2017.

[64] Internet World Stats, Middle East Internet Statistics, Population, Facebook and Telecommunications Reports, 2017.

[65] M. Fisher, How did Syria cut off the entire country from the Internet? The Washington Post, 2013, May 8.

[66] K. Andén-Papadopoulos and M. Pantti, The Media Work of Syrian Diaspora Activists: Brokering Between the Protest and Mainstream Media, International Journal of Communication, 7, 2013.

[67] L. Harding and C. Arthur, Syrian Electronic Army: Assad's cyber warriors, The Guardian, 2013, April 30.

[68] N. Thompson, Why Did Syria Shut Down the Internet? The New Yorker, 2013, May 8.

[69] J. R. Halverson, S. W. Ruston and A. Trethewey, Mediated Martyrs of the Arab Spring: New Media, Civil Religion, and Narrative in Tunisia and Egypt, Journal of Communication, 63(2), 312-332, 2013.

[70] B. Klandermans and S. Staggenborg, Methods of Social Movement Research, U of Minnesota Press, 2002.

[71] W. B. Gudykunst, Cross-Cultural and Intercultural Communication, SAGE, 2003.

[72] M. J. Dutta, Decolonizing Communication for Social Change: A Culture-Centered Approach: Decolonizing Communication for Social Change, Communication Theory, 25(2), 123-143, 2015.

[73] R. Fletcher, A. Cornia, L. Graves, and R. K. Nielsen, Measuring the reach of "fake news" and online disinformation in Europe, Reuters Institute, The University of Oxford. 